\title{
EXTRAÇÃO DE COMPOSTOS BIOATIVOS DA CASCA DE PASSIFLORA EDULIS.sSP COM DIFERENTES SOLVENTES
}

\author{
C. G. de SOUZA ${ }^{1,2}$, M.V.L. SOARES ${ }^{1,2}$, RIBEIRO, P.R.V ${ }^{2}$ e E.S de BRITO ${ }^{2}$ \\ ${ }^{1}$ Universidade Federal do Ceará, Departamento de Engenharia Química \\ ${ }^{2}$ Embrapa Agroindústria Tropical \\ e-mail: carolinegondimdesouza@ hotmail.com
}

\begin{abstract}
RESUMO - Um dos principais desafios da indústria alimentícia é o reaproveitamento de resíduos gerados no processamento, assim estes detritos podem ser convertidos em produtos com valor agregado, além de minimizarem os impactos ambientais. Os resíduos produzidos durante a produção do suco de maracujá possuem níveis consideráveis de compostos bioativos que têm diversas propriedades funcionais. No presente estudo objetivou-se verificar a presença de substâncias bioativas na casca de Passiflora edulis e analisar o rendimento das extrações. As extrações foram realizadas em extrator automático com solvente acelerado. Os solventes utilizados foram: água, soluções de metanol: água e etanol: água na proporção 80: 20(v/v), respectivamente. Os solventes foram evaporados e as amostras liofilizadas. Posteriormente foram realizadas análises em LC-MS e verificação de rendimento. Os resultados apontam a presença de compostos fenólicos, principalmente flavonoides e rendimentos de 17, 29 e 30\% para água, etanol: água e metanol: água, respectivamente.
\end{abstract}

\section{INTRODUÇÃO}

O gênero Passiflora compreende cerca de 450 a 600 espécies de maracujazeiros, onde 150 originárias do Brasil (Ferreira 2005, Faleiro et al., 2008). O Brasil é o principal produtor e consumidor mundial de maracujá. Conforme censo do Instituto Brasileiro de Geografia e Estatística (IBGE, 2012), o país produziu 923 mil toneladas de maracujá em 2011. As principais utilizações do fruto do maracujazeiro no processo produtivo é a sua comercialização in natura, e o seu beneficiamento em indústrias de sucos. Um dos principais desafios para a indústria é converter os resíduos gerados durante o processamento em produtos com valor agregado visando minimizar os impactos ambientais causados por estes detritos (De Oliveira et al., 2012). O emprego dos resíduos agroalimentar de maneira eficiente, com um menor custo e ambientalmente correta é altamente rentável. Uma das alternativas mais eficazes para o aproveitamento deste resíduo é a recuperação de constituintes bioativos alimentares, o que é economicamente vantajosa para as indústrias farmacêuticas, indústria de cosméticos e de alimentos (De Oliveira et al., 2009).

Os compostos bioativos em plantas têm sido potencialmente estudados nos últimos anos, devido à crescente popularidade dos produtos naturais e de seus benefícios à saúde. Várias pesquisas estão sendo realizadas em todo mundo para verificar o valor nutritivo das frutas. A identificação das características físico-químicas e a quantificação das substâncias bioativas são de interesse para acrescentar qualidade nutricional e valor ao produto final (De Souza et al., 2012). 
Estudos referentes à composição química de diversas espécies de Passiflora edulis mostram principalmente a presença de flavonoides C-glicosídeos (Zeraik et al., 2011). Estes compostos possuem uma grande diversidade de atividade biológica, apresentando funções antioxidantes, efeitos anti-inflamatórios, efeito vasodilatador, ação antialérgica, atividade contra o desenvolvimento de tumores, antihepatotóxica, antiulcerogênica, atuação antiplaquetária, bem como ações antimicrobianas e antivirais (Ye et al., 2011) .

Diversas metodologias de extração foram desenvolvidas nos últimos anos, visando diminuir o tempo de processo, reduzir o uso de solventes orgânicos, e elevar a eficiência da extração, assim tendo por finalidade reduzir os custos de processo e consequentemente diminuir a poluição ambiental (Huang et al., 2013). Para tal processo vários tipos de solventes são utilizados: metanol, etanol, acetona ou a sua combinação com a água, acetato de etila e também por destilação a vapor. As ótimas condições de extração dependem do composto bioativo em questão e do tipo de material que está sendo analisado (Biesaga, 2011). No presente estudo objetivou-se verificar a presença de substâncias bioativas na casca de Passiflora edulis e analisar o rendimento das extrações utilizando diferentes solventes.

\section{MATERIAIS E MÉTODOS}

\subsection{Coleta e preparo das cascas para extração}

Neste estudo foram utilizados frutos de Passiflora edulis ssp., adquiridos na Central de Abastecimento S/A de Fortaleza - CEASA-CE.. Os furtos foram higienizados e posteriormente despolpados. As cascas foram picadas e secas em estufa de circulação de ar a $60^{\circ} \mathrm{C}$ por 48 horas, em seguida foram moídas em moinho de facas tipo WILLEY, modelo BT 602 , a granulometria da farinha utilizada foi de $50 \mathrm{~mm}$.

\subsection{Condições de processo}

As extrações foram realizadas em extrator automático com solvente acelerado (ASE 350, Dionex). Inicialmente pesou-se $2 \mathrm{~g}$ de amostra e misturou-se com $4 \mathrm{~g}$ de terra diatomácea, posteriormente colocou-se em uma célula de extração de aço inoxidável com volume de $66 \mathrm{ml}$. As condições de processo: temperatura de $80^{\circ} \mathrm{C}$; rinse de 5 minutos; tempo de extração de 10 minutos em cada ciclo e purga de 200 segundos. Os solventes utilizados foram: água, soluções de metanol: água e etanol: água na proporção 80:20 (v/v), respectivamente. Os experimentos foram realizados em triplicata. Os solventes foram evaporados e as amostras liofilizadas.

\subsection{Determinações analíticas}

A presença de compostos bioativos foi verificada por cromatografia líquida e espectrofotometria de massa no equipamento UPLC (Aquity) e QToF (Xevo). Foi utilizada a coluna analítica Acquity UOLC BEH C18 $(1,7 \mu \mathrm{m}, 2.1 \mathrm{~mm}$ x $150 \mathrm{~mm})$ com fluxo de $0,5 \mathrm{~mL} / \mathrm{min}$, volume de injeção de $1 \mu \mathrm{L}$ e o tempo total da corrida foi de 15 minutos. A fase móvel utilizada foi água / ácido fórmico $0,1 \%$ e acetonitrila / ácido fórmico $0,1 \%$ (v/v). O rendimento das extrações foi calculado baseado na razão entre a massa em gramas de extrato obtido ao final do processo e a massa em gramas de farinha em base seca da casca de Passiflora edulis. 


\section{Resultados e discussão}

Os resultados da análise de LC-MS apontam o mesmo perfil cromatográfico, estando representados pela figura 1 (a). Este resultado indica que o tipo de solvente não influenciou as extrações das substâncias, tendo extraído substâncias de massas semelhantes. Foram selecionados 6 picos cromatográficos relevantes figura1(b), que apareceram com maior frequência nos cromatogramas. Os compostos foram reconhecidos a partir de dados das massas moleculares obtidos na análise de LC-MS e subsequente confirmação por comparação com dados da literatura (Tabela 1).

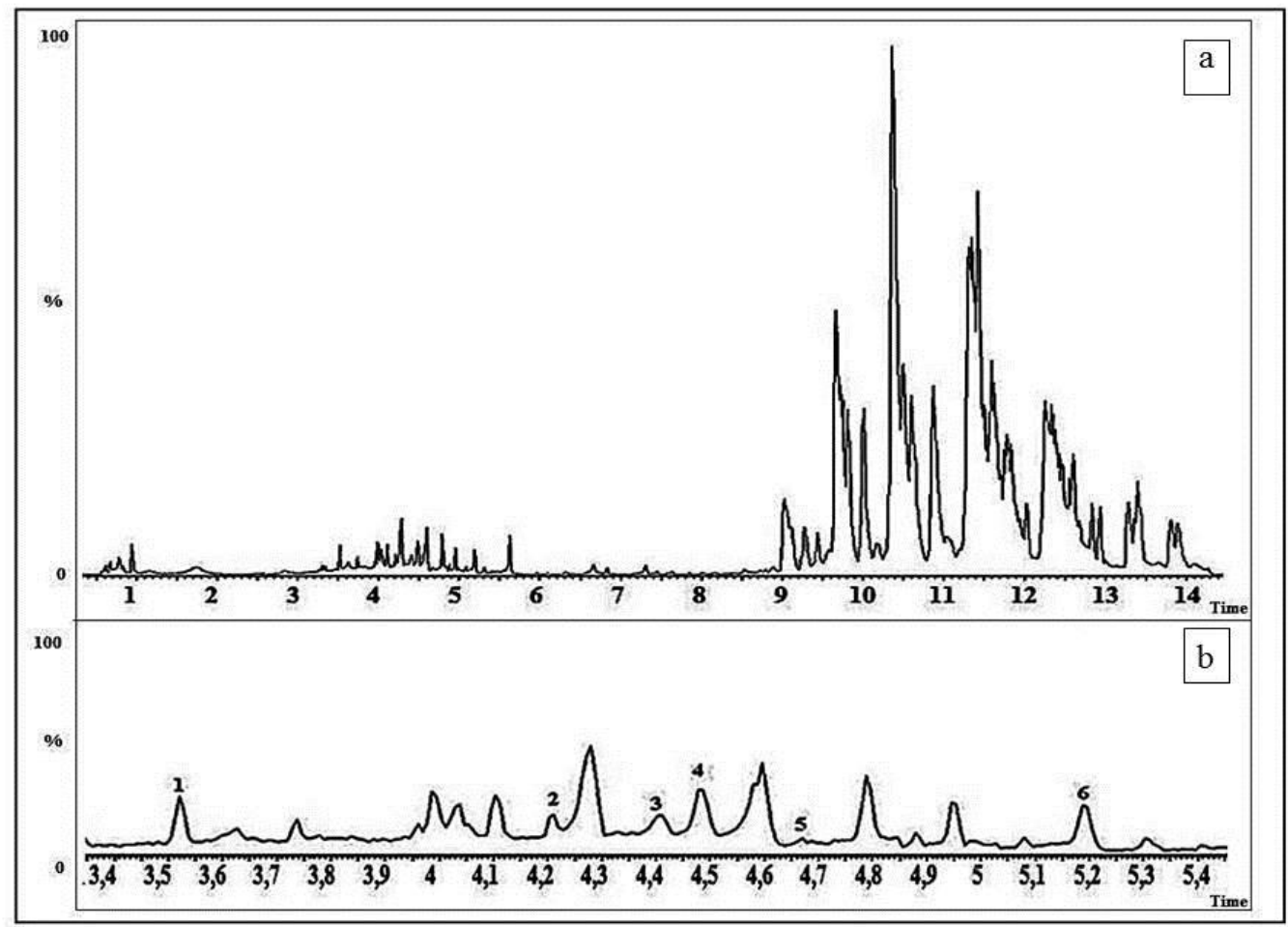

Figura 1: Perfil cromatográfico extração realizada com Metanol: Água (a) e região ampliada referente aos picos identificados (b).

Tabela 1- Composto mais frequentes encontrados nos cromatogramas

\begin{tabular}{|c|c|c|c|c|c|c|}
\hline Pico & $\begin{array}{c}\text { Tempo } \\
\text { retençãao } \\
(\text { min) }\end{array}$ & $\begin{array}{l}\text { Fórmula } \\
\text { Molecular }\end{array}$ & $\begin{array}{c}{[\mathrm{M}-\mathrm{H}]^{-}} \\
\text {Experimental }\end{array}$ & $\begin{array}{l}{[\mathrm{M}-\mathrm{H}]^{-}} \\
\text {Literatura }\end{array}$ & Substância & $\begin{array}{l}\text { Referência } \\
\text { Bibliográfica }\end{array}$ \\
\hline 1 & 3,512 & & 609,15 & 609,20 & $\begin{array}{l}\text { isoorientina-2"- } \\
\text { O-glucosideo }\end{array}$ & $\begin{array}{l}\text { (Sakalem, Negri } \\
\text { e Tabach, 2012) }\end{array}$ \\
\hline 2 & 4,211 & $\mathrm{C}_{21} \mathrm{H}_{20} \mathrm{O}_{11}$ & 447,09 & 447,09 & Orientina & (Ma et al., 2013) \\
\hline 3 & 4,337 & $\mathrm{C}_{27} \mathrm{H}_{30} \mathrm{O}_{15}$ & 593,15 & 593,00 & Vicenina-2 & $\begin{array}{c}\text { (Zucolotto et al. } \\
\text { 2012) }\end{array}$ \\
\hline 4 & 4,479 & $\mathrm{C}_{26} \mathrm{H}_{28} \mathrm{O}_{14}$ & 563,14 & 563,00 & $\begin{array}{l}\text { isoschaftoside } \\
\text { /schaftoside }\end{array}$ & $\begin{array}{l}\text { (Sakalem, Negri } \\
\text { e Tabach, 2012) }\end{array}$ \\
\hline 5 & 4,679 & & 577,16 & 577,00 & $\begin{array}{c}\text { 6,8-di-C- } \\
\text { glycosylchrysin }\end{array}$ & $\begin{array}{c}\text { (Zucolotto et al. } \\
\text { 2012) }\end{array}$ \\
\hline 6 & 5,188 & $\mathrm{C}_{21} \mathrm{H}_{20} \mathrm{O}_{10}$ & 431,10 & 431,10 & Vitexina & (Ma et al., 2013) \\
\hline
\end{tabular}


Os resultados apontam a presença de compostos fenólicos. Zucolotto et al., $2012 \mathrm{em}$ seus experimentos também encontraram algumas substâncias bioativas, predominando a presença de flavonoides C-glicosídeos. Os flavonoides C-glicosídeos identificados com maior frequência foram orientina, isoorientina, vitexina e isovitexina.

Os flavonoides encontrados no presente estudo possuem diversas propriedades benéficas. LeeW et.al., 2014 relataram em seus experimentos que a orientina e a isoorientina podem ser consideradas como um potencial candidato no tratamento de doenças inflamatórias de origem vasculares. R. Praveena et.al., 2014 evidenciaram que a vitexina, isovitexina, orientina, isoorientina e vicenina-2 atuam como uma fonte rica em antioxidantes. Também foi descrito que a orientina é mais eficiente na retirada de radicais oxidativos em comparação com vitexina. Md. Nurul Islam et.al, 2014 descreveram diversos efeitos benéficos associados a vicentina-2: antioxidantes, antihepatotóxica, antiespasmódico e melhora do desconforto gastrointestinal.

De acordo com o seu alto valor nutricional e conteúdo de flavonoides, verificações sobre a potencialidade da casca de maracujá como alimento funcional, ou uma fonte de substâncias bioativas são de suma importância (Zeraik et al., 2011). A grande maioria dos flavonoides possuem propriedades biológicas e químicas em comum: atividade antioxidante, habilidade de retirar espécies reativas de oxigênio, capacidade de sequestrar eletrólitos, potencial para gerar peroxido de hidrogênio quando entra em contato com alguns metais, aptidão de modular a ação de algumas enzimas celulares. Uma alimentação rica em flavonoides pode proteger contra diversos tipos de doenças: doenças cardiovasculares, distúrbios neurodegenerativos e alguns tipos de câncer (Damodaram, Parkin e Fennema, 2010). Alguns flavonoides também possuem a capacidade de inibir a replicação viral do agente causador da Síndrome da Imunodeficiência Humana (HIV) (Mantas et al., 2000).

Na tabela 2 encontram-se as médias das triplicatas dos rendimentos das extrações. Pode-se notar que as extrações realizadas com metanol: água e etanol: água apresentaram rendimentos maiores cerca de 30 e $29 \%$, respectivamente.

Tabela 2 - Rendimento das extrações

\begin{tabular}{|c|c|}
\hline Solventes & Rendimento (\%) \\
\hline Metanol: Água & 30 \\
\hline Etanol: Água & 29 \\
\hline Água & 17 \\
\hline
\end{tabular}

Solventes alcoólicos estão sendo comumente empregados para extração de compostos fenólicos oriundos de fontes naturais, eles fornecem um rendimento muito elevado de extrato total. Em particular, misturas de alcoóis e água revelaram-se mais eficientes na extração de constituintes fenólicos do que o correspondente monocomponente do sistema solvente (Gironi e Piemonte, 2011). Esta mistura de solvente com a água proporciona um aumento da polaridade do solvente, com isso maiores teores de compostos fenólicos podem ser extraídos (Sultana et al., 2007, WIjekoon et al., 2011, Hussain et al., 2012).

Um fator que deve ser considerado para o baixo rendimento das extrações obtidas utilizando água como solvente, é que na etapa de evaporação das amostras ocorreu a gelatinização da mesma, como mostrado na Figura 3. Este fato deve-se a presença de pectina 
presente na casca de Passiflora edulis, assim ocorreu perda de amostra durante este processo.

Apesar dos extratos obtidos utilizando água como solvente apresentarem menor rendimento em comparação com outras soluções solventes analisadas, a utilização de água subcrítica como meio reacional tem aumentado devido: a água é barata, não-tóxica, não é um combustível, atua como solvente e parceira de reações, é ambientalmente segura, extremamente reativa e água subcrítica pode agir como um catalisador ácido ou básico (Ko et al., 2011).

\section{Conclusão}

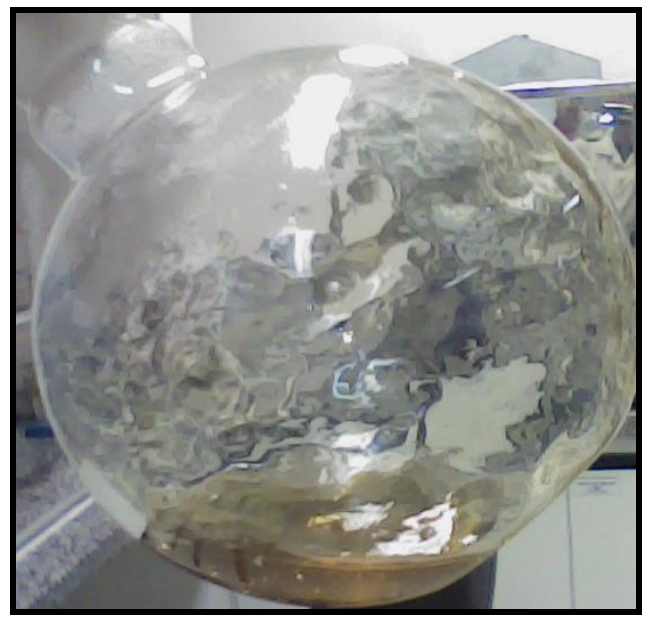

Figura 3 - Gelatinização da amostra.

O presente estudo indica a presença de compostos fenólicos na casca de maracujá (orientina, isoorientina-2"-O-glucosideo, 6,8-di-C-glycosylchrysin, isoschaftoside, schaftoside e vitexina). A extração dos compostos pode ser realizada utilizando qualquer solvente analisado, pois não apresentou diferença significativa entre os perfis cromatográficos. Entretanto, observou-se diferença entre os volumes de extratos totais e problemas com a gelatinização da amostra utilizando água como solvente, assim o melhor solvente para a realização das extrações dos compostos é com o metanol e etanol. Deve-se ressaltar que apesar do metanol ser considerado como um solvente seguro, algumas legislações limitam sua utilização em alimentos, assim o solvente mais indicado é o etanol. Estudos futuros devem ser realizados visando diminuir o uso do solvente durante o processo de extração, tornando o processo mais ambientalmente correto, portanto combinações de etanol e água em várias concentrações devem ser testadas.

\section{Referencia}

BIESAGA, M. Influence of extraction methods on stability of flavonoids. Journal of Chromatography a, v. 1218, n. 18, p. 2505-2512, MAY 62011 2011. ISSN 0021-9673.

DAMODARAM, S.; PARKIN, K. L.; FENNEMA, O. R. Química de Alimentos de Fennema. $4^{\circ}$ ed.Porto Alegre: 2010. 900p.

DE OLIVEIRA, A. et al. Total phenolic content and free radical scavenging activities of methanolic extract powders of tropical fruit residues. Food Chemistry, v. 115, n. 2, p. 469475, JUL 152009 2009. ISSN 0308-8146. 
DE OLIVEIRA, L. et al. Characterization and extraction of volatile compounds from passion fruit (Passiflora edulis Sims f. flavicarpa Degener) processing waste. Ciencia Rural, v. 42, n. 12, p. 2280-2287, DEC 2012 2012. ISSN 0103-8478.

DE SOUZA, V. et al. Determination of bioactive compounds, antioxidant activity and chemical composition of Cerrado Brazilian fruits. Food Chemistry, v. 134, n. 1, p. 381-386, SEP 12012 2012. ISSN 0308-8146.

FALEIRO, FG; OLIVEIRA, EJ; ANDRADE, SEM; COSTA, AM; JUNQUEIRA, NTV. Biotecnologia aplicada à cultura do maracujazeiro. IN.:. 2012 FALEIRO, F. G.; JUNQUEIRA, N. T. V.; FÁVERO, A. P.; LOPES, M. A. Pré-melhoramento de Plantas: experiências de sucesso. In: FALEIRO, F. G.; FARIAS NETO, A. L.; RIBEIRO

FERREIRA, F. R. Recursos Genéticos de Passiflora. In: FALEIRO, F. G.; JUNQUEIRA, N. T. V.; BRAGA, M. F. (Eds). Maracujá: germoplasma e melhoramento genético. Planaltina: Embrapa Cerrados, 2005. p. 41-51.

GIRONI, F.; PIEMONTE, V. Temperature and solvent effects on polyphenol extraction process from chestnut tree wood. Chemical Engineering Research and Design, v. 89, n. 7, p. 857-862, 2011.

HUANG, $\mathrm{H}$. et al. Advances in the extraction of natural ingredients by high pressure extraction technology. Trends in Food Science \& Technology, v. 33, n. 1, p. 54-62, SEP 2013 2013. ISSN 0924-2244.

HUSSAIN, A. I.; CHATHA, S. A. S.; NOOR, S.; KHAN, Z. A.; ARSHAD, M. U.; RATHORE, H. A.; SATTAR, M. Z. A. Effect of Extraction Techniques and Solvent Systems on the Extraction of Antioxidant Components from Peanut (Arachis hypogaea L.) Hulls. Food Analytical Methods, v. 5, n. 4, p. 890-896, 2012.

IBGE - Instituto Brasileiro de Geografia e Estatística. Dados demográficos e produção agrícola municipal. Rio de Janeiro, 2012.v.72, 170p.

$\mathrm{KO}, \mathrm{M}$. et al. Subcritical water extraction of flavonol quercetin from onion skin. Journal of Food Engineering, v. 102, n. 4, p. 327-333, FEB 2011 2011. ISSN 0260-8774.

Lee W, et al, Vascular barrier protective effects of orientin and isoorientin in LPS-induced inflammation in vitro and in vivo..., Vascul. Pharmacol. (2014), http://dx.doi.org/10.1016/j.vph.2014.04.006

MA, C. et al. Antioxidant and Metabolite Profiling of North American and Neotropical Blueberries Using LC-TOF-MS and Multivariate Analyses. Journal of Agricultural and Food Chemistry, v. 61, n. 14, p. 3548-3559, Apr 10 2013. ISSN 0021-8561. Disponível em: $<<$ Go to ISI $>$ ://WOS:000317548500024 >.

MANTAS, A. et al. Structural analysis of flavonoids with anti-HIV activity. Journal of Molecular Structure-Theochem, v. 504, p. 171-179, JUN 122000 2000. ISSN 0166-1280.

Md. Nurul Islam, Ishrat Jahan Ishita, Hyun Ah Jung, Jae Sue Choi, Vicenin 2 isolated from Artemisia capillaris exhibited potent anti-glycation properties, Food and Chemical Toxicology, Volume 69, July 2014, Pages 55-62, ISSN 0278-6915, http://dx.doi.org/10.1016/j.fct.2014.03.042. Disponível em: http://www.sciencedirect.com/science/article/pii/S0278691514001793.

R. Praveena, K. Sadasivam, V. Deepha, Raman Sivakumar, Antioxidant potential of orientin: A combined experimental and DFT approach, Journal of Molecular Structure, Volume 1061, 5 March 2014, Pages 114-123, ISSN 0022-2860, http://dx.doi.org/10.1016/j.molstruc.2014.01.002.

Disponível em: 
http://www.sciencedirect.com/science/article/pii/S0022286014000192 >.

SAKALEM, M. E.; NEGRI, G.; TABACH, R. Chemical composition of hydroethanolic extracts from five species of the Passiflora genus. Revista Brasileira De FarmacognosiaBrazilian Journal of Pharmacognosy, v. 22, n. 6, p. 1219-1232, Nov-Dec 2012. ISSN 0102695X. Disponível em: < <Go to ISI>://WOS:000312200500004 >.

SULTANA, B.; ANWAR, F.; PRZYBYLSKI, R. Antioxidant activity of phenolic components present in barks of Azadirachta indica, Terminalia arjuna, Acacia nilotica, and Eugenia jambolana Lam. trees. Food Chemistry, v. 104, n. 3, p. 1106-1114, 2007.

WIJEKOON, M. M. J. O.; BHAT, R.; KARIM, A. A. Effect of extraction solvents on the phenolic compounds and antioxidant activities of bunga kantan (Etlingera elatior Jack.) inflorescence. Journal of Food Composition and Analysis, v. 24, n. 4-5, p. 615-619, 2011.

YE, X. et al. Identification of bioactive composition and antioxidant activity in young mandarin fruits. Food Chemistry, v. 124, n. 4, p. 1561-1566, FEB 152011 2011. ISSN 0308-8146.

ZERAIK, M. et al. Evaluation of the antioxidant activity of passion fruit (Passiflora edulis and Passiflora alata) extracts on stimulated neutrophils and myeloperoxidase activity assays. Food Chemistry, v. 128, n. 2, p. 259-265, SEP 152011 2011. ISSN 0308-8146.

ZUCOLOTTO, S. M. et al. Analysis of C-glycosyl Flavonoids from South American Passiflora Species by HPLC-DAD and HPLC-MS Phytochemical Analysis Volume 23, Issue 3. Phytochemical Analysis. 23: 232-239 p. 2012. 